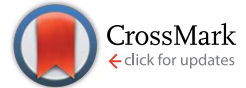

Cite this: Chem. Sci., 2016, 7, 5230

\section{NIR in, far-red out: developing a two-photon fluorescent probe for tracking nitric oxide in deep tissue $\uparrow$}

\author{
Zhiqiang Mao, Wenqi Feng, Zhen Li, Lingyu Zeng, Weijie Lv and Zhihong Liu*
}

As a pivotal signalling molecule involved in various physiological and pathological processes, nitric oxide (NO) has motivated increasing interest in the last few decades. Although a considerable number of fluorescent probes have been developed for NO imaging, the in situ tracking of this gas molecule in biological events remains a big challenge, mainly because of the relatively short excitation and/or emission wavelengths, which are subject to background interference and lowered collection efficiency in deep-tissue imaging. Herein, we report a far-red emissive $(650 \mathrm{~nm})$ two-photon (TP) excitable NRNO probe, using Nile Red as the TP fluorophore, for NO detection and imaging both in vitro and in vivo. The NRNO probe shows a fast (within $180 \mathrm{~s}$ ) and specific fluorescence response toward NO with a limit of detection (LOD) as low as $46 \mathrm{nM}$. The excellent properties of NRNO enable it to sensitively detect both exogenously and endogenously generated NO in living cells. The "NIR in" and "far-red out" lights lead to improved penetrating ability, thus endowing the probe with high resolution for the illumination of deep tissues. It is therefore able to visualize the NO generation in a lipopolysaccharide (LPS)-mediated inflammation process for the first time. Our results demonstrate that NRNO could be a practical tool for studying the NO-related biological events. Moreover, this study also suggests the possibility of using Nile Red and its derivatives to develop far-red emissive TP probes, which is an important, yet undeveloped area.
Received 23rd March 2016 Accepted 22nd April 2016

DOI: $10.1039 / c 6 s c 01313 a$

www.rsc.org/chemicalscience dynamics of this gas at the cellular and tissue levels is an ongoing focus of investigations.

Small-molecule based fluorescence imaging has shown promise and has become an indispensable tool for studying biological specimens in life sciences, owing to its high sensitivity, specificity, real-time detection and non-invasive features, as well as technical simplicity. To date, two main types of fluorescent probes, i.e., o-phenylenediamine and transition metal based organic dyes and complexes, have been developed to detect NO in aqueous media and cells. ${ }^{5}$ Despite the appreciable progress made in this area, very few probes are competent for practical applications, mainly because of their photophysical limitations; i.e., their relatively short excitation/ emission wavelengths restrict the illumination of deep issues with minimized background. ${ }^{6}$

It has been established that with the use of two-photon probes, which simultaneously absorb two NIR photons (700$900 \mathrm{~nm}$ ), comes the ability to acquire deeper penetration, reduce background fluorescence and provide higher 3D temporal-spatial resolution than one-photon probes. ${ }^{7}$ During the last few years, several two-photon fluorescent probes for NO imaging in cells and tissues have been exploited by some groups and have contributed considerably to the understanding of the biological roles of NO. ${ }^{8}$ However, these TP probes circumvent only half of the above problem (by locating the excitation in the NIR region), and the deficiency with emission wavelength still 
exists; i.e., all these TP probes emit in the green region or shorter wavelength $(<550 \mathrm{~nm})$. The short emission wavelength somewhat impairs the aforementioned advantages of TP probes in bio-imaging, since some intrinsic biomolecules (such as $\mathrm{NADH}$, riboflavin, and folic acid etc.) also can be two-photon excited and lead to background fluorescence in the blue to green region. ${ }^{9}$ Meanwhile, the $<550 \mathrm{~nm}$ emission of the TP probes can be absorbed by biomolecules like hemoglobin $(\mathrm{Hb})$ and oxyhemoglobin $\left(\mathrm{HbO}_{2}\right)$, which decrease the collection efficiency of the fluorescence signal in deep imaging. ${ }^{10}$ Therefore, it would be more significant to develop TP probes with the emission in the far-red to NIR region, which is much less absorbed by biomolecules and penetrates deeper into tissues, so as to further minimize the interference from background fluorescence and increase the collection efficiency. ${ }^{11}$ Until now, due to the limitations of the fluorophores, which should possess both a large TP cross section and long-wavelength emission, far-red emissive ${ }^{12}$ TP fluorescent probes have rarely been reported.

In this work, we designed and synthesized a far-red emissive two-photon fluorescent probe for the detection of nitric oxide in living systems. The NRNO probe exhibited a prominent fluorescence enhancement upon reaction with $\mathrm{NO}$ in the far-red region in a short time, with excellent selectivity and high sensitivity. Owing to its photophysical merits, the probe was successfully used to measure both exogenous and endogenous NO in living cells. It was also able to vividly image NO in liver tissue slices of mice at a depth up to $170 \mu \mathrm{m}$ with high resolution, and thus, it was capable of monitoring the production of NO in the LPS-mediated inflammation process. To the best of our knowledge, this is the first far-red emissive two-photon probe for nitric oxide that realizes the in situ tracking of NO in the pathological event.

\section{Results and discussion}

\section{Design and synthesis of NRNO}

Despite the advancement of TP microscopy in the last decade, TP probes with far-red/NIR emission are rarely reported. The main reason is the lack of long-wavelength emissive TP fluorophores with sufficient two-photon action cross sections. In our design of NRNO, we chose Nile Red as the fluorescence reporting unit for its attractive photophysical properties, including the long emission wavelength $(>600 \mathrm{~nm})$, large extinction coefficient and good photostability. ${ }^{13}$ Owing to the easily polarized electronic structure and large conjugated $\pi$ system, ${ }^{14}$ we speculated that Nile Red might be an excellent platform for developing red-emissive two-photon probes. $O$-Phenylenediamine was selected as the receptor of nitric oxide for its specific response and high sensitivity, and it is a common photoinduced electron transfer (PET) quencher for most fluorophores..$^{15}$ On the other hand, it is well-established that the PET quenching efficiency is distance dependent; i.e., it decreases with increasing distance between the electron donor and electron acceptor. ${ }^{16}$ To guarantee the efficiency of fluorescence quenching, we covalently linked the fluorescence reporting unit and $o$-phenylenediamine unit with a short oxygen-containing, four-membered chain $\left(-\mathrm{OCH}_{2} \mathrm{CH}_{2} \mathrm{O}-\right.$, Scheme 1). It is envisioned that the NRNO probe shows weak fluorescence due to the PET effect of the $o$-phenylenediamine unit. When NRNO reacts with nitric oxide under aerobic conditions, the $o$-phenylenediamine transforms into triazole and the product should emit intensely in the far-red region because of the inhibition of the PET effect (Scheme 1). The compound NRNO was synthesized and characterized by ${ }^{1} \mathrm{H}$ NMR, ${ }^{13} \mathrm{C}$ NMR and HR-MS spectra (Fig. S1 and S8-S16, ESI $\dagger$ ).

\section{Spectroscopic properties of NRNO and its response toward NO}

We first evaluated the fluorescence properties of NRNO $(5.0 \mu \mathrm{M})$ in $10 \mathrm{mM}$ PBS ( $\mathrm{pH}=7.4$, containing $10 \%$ DMF as co-solvent). The NRNO probe showed absorption and emission maxima at $583 \mathrm{~nm}\left(\varepsilon=4.00 \times 10^{4} \mathrm{M}^{-1} \mathrm{~cm}^{-1}\right)$ and $648 \mathrm{~nm}$, respectively. The emission of NRNO in the far-red region is longer than that of previous NO probes, which can be beneficial to imaging in biological samples. The very weak fluorescence at $648 \mathrm{~nm}$ (with $\Phi=0.03)$ is ascribed to the effective PET process. Upon reaction with excess NO, remarkable fluorescence enhancement was observed as a result of the blocking of the PET process, and the product showed an intense fluorescence emission band centered at $650 \mathrm{~nm}(\Phi=0.42)$ under the excitation of $585 \mathrm{~nm}(\varepsilon$ $=3.96 \times 10^{4} \mathrm{M}^{-1} \mathrm{~cm}^{-1}$ ) (Table S1 and Fig. S2, ESI $\dagger$ ). The significant reaction-induced enhancement of the fluorescence quantum yield suggests that NRNO is suitable for use in aqueous media and rationalizes our probe design as well. We then conducted fluorescence titration of $5.0 \mu \mathrm{M}$ of probe with external standard NO for in vitro detection. Firstly, we examined the kinetics of the reaction between the probe and target. The addition of 6.0 eq. of $\mathrm{NO}$ to the probe solution at $37^{\circ} \mathrm{C}$ led to an immediate 7.4-fold increase in fluorescence intensity in 60 seconds. The signal intensity of the reaction reached a plateau at only $180 \mathrm{~s}$ with a fluorescence enhancement factor $\left(F / F_{0}\right)$ of ca. 8.4-fold (Fig. 1a and b). The fast response of the NRNO probe towards NO is very favourable for the real-time detection of NO in living systems. The fluorescence intensity of the reaction at $650 \mathrm{~nm}$ also increased linearly with the concentration of NO in the range of 1.0-26.0 $\mu \mathrm{M}\left(R^{2}=0.999\right)$ (Fig. 1c and d). The limit

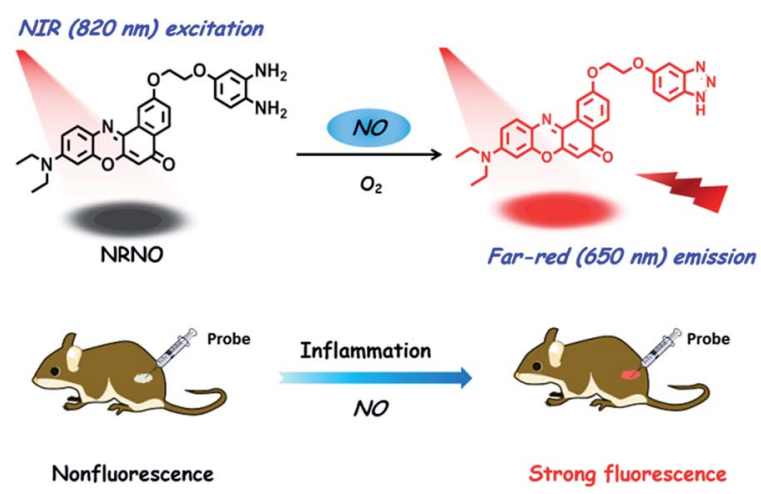

Scheme 1 Design of the far-red emissive two-photon fluorescent probe, NRNO, for nitric oxide (NO) and its application in the detection of nitric oxide in inflamed tissues. 

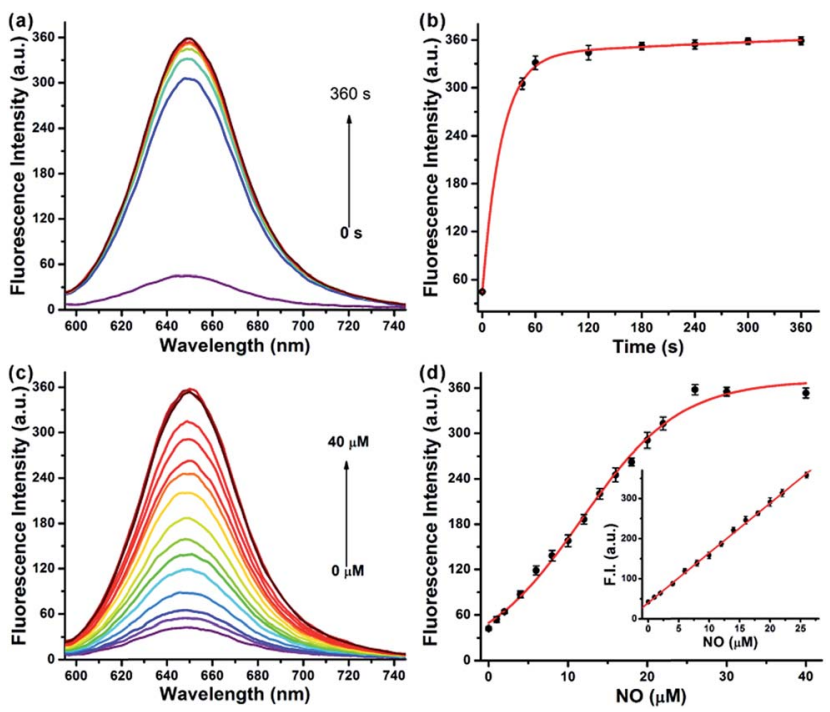

Fig. 1 (a) Fluorescence spectra for the reaction of $5.0 \mu \mathrm{M}$ NRNO with excess $\mathrm{NO}(30 \mu \mathrm{M})$ with time. (b) Plot of fluorescence intensity vs. time $(0-360 \mathrm{~s})$ for the reaction of $5.0 \mu \mathrm{M}$ NRNO with $30 \mu \mathrm{M}$ NO. (c) Fluorescence spectra of $5.0 \mu \mathrm{M}$ NRNO with $\mathrm{NO}(0-40 \mu \mathrm{M})$ after reacting for $180 \mathrm{~s}$. (d) Fluorescence intensity of NRNO as a function of NO concentration $(0-40 \mu \mathrm{M})$. Inset: the linear relationship between fluorescence intensity and NO concentration within 1.0-26 $\mu \mathrm{M}$. The excitation wavelength was $585 \mathrm{~nm}$, and the fluorescence intensity was measured at $650 \mathrm{~nm}$. Measurements were done in $10 \mathrm{mM}$ PBS $(\mathrm{pH}=$ 7.4 , containing $10 \%$ DMF).

of detection (LOD) for nitric oxide as calculated by $3 \sigma / m$ criteria (where $m$ is the slope for the range of the linearity used and $\sigma$ is the standard deviation of the blank, $n=11$ ) was $46 \mathrm{nM}$, which represents a high enough sensitivity for the detection of physiological NO level (nanomole to micromole). ${ }^{17}$

\section{Selectivity and $\mathrm{pH}$ independence of NRNO}

The selectivity of the NRNO probe toward NO over other biologically relevant species was investigated. We examined the fluorescence response of NRNO to NO and other possible interfering molecules and ions, which include $50 \mu \mathrm{M}$ metal ions $\left(\mathrm{Ca}^{2+}, \mathrm{Mg}^{2+}, \mathrm{Zn}^{2+}, \mathrm{Mn}^{2+}, \mathrm{Fe}^{2+}\right), 1.0 \mathrm{mM}$ biothiols (GSH, Cys, Hcy), $30 \mu \mathrm{M}$ reactive oxygen species $\left({ }^{\circ} \mathrm{OH},{ }^{1} \mathrm{O}_{2}, \mathrm{H}_{2} \mathrm{O}_{2}, \mathrm{ClO}^{-}, \mathrm{O}_{2}{ }^{-}\right)$and reactive nitrogen species $\left(\mathrm{NO}_{2}{ }^{-}, \mathrm{ONOO}^{-}\right)$. As shown in Fig. $\mathrm{S} 3, \dagger$ none of the above interfering species caused obvious fluorescence intensity enhancement of NRNO, and the response of NRNO toward NO was not affected by the coexistence of these species. The effect of $\mathrm{pH}$ on the NRNO probe in the absence and presence of NO were also studied. As shown in Fig. $\mathrm{S} 4, \dagger$ both the probe itself and the reaction product were insensitive to $\mathrm{pH}$ in the physiological range of 6.0-8.5. These properties ensure the reliability of using NRNO to detect NO in biological environments.

\section{TP fluorescence properties of NRNO}

The two-photon action cross sections $(\Phi \delta)$ of a probe before and after reacting with the target are crucial parameters for twophoton microscopy, which generally determine the signal enhancement factor and the signal-to-background ratio under the microscope. The two-photon action cross sections of NRNO in the absence and presence of NO were measured in the $10 \mathrm{mM}$ PBS ( $\mathrm{pH}=7.4$, containing 10\% DMF as co-solvent). Similar to the above mentioned very low quantum yield, the NRNO probe itself possessed an extremely low TP action cross section, which was non-detectable under our experimental conditions, while the reaction product of NRNO and NO showed the maximal TP action cross section value of $38 \mathrm{GM}\left(1 \mathrm{GM}=10^{-50} \mathrm{~cm}^{4} \mathrm{~s}\right.$ per photon per molecule) at $820 \mathrm{~nm}$ (Table S1 and Fig. S5, ESI $\dagger$ ). This result indicates that the probe has a distinct change in TP fluorescence properties before and after reacting with the target, which implies that NRNO is suitable for tracking NO under TP excitation.

\section{TP imaging of exogenous and endogenous NO in living cells}

Based on the promising photophysical properties of NRNO and its rapid and selective response to NO, we proceeded to utilize NRNO to track NO level in living cells. The cytotoxicity of NRNO was first evaluated by MTT assays with HeLa cells. HeLa cells were incubated with various concentrations $(5-40 \mu \mathrm{M})$ of NRNO, and the results showed that the cells had a high viability (>90\%) even when treated with $25 \mu \mathrm{M}$ NRNO after $24 \mathrm{~h}$, demonstrating the low cytotoxicity of the probe (Fig. S6, ESI $\dagger$ ). To clarify the intracellular localization of the probe, HeLa cells were co-incubated with NRNO and a well-known nucleus staining dye, Hoechst 33258. ${ }^{\mathbf{1 8}}$ The NRNO and Hoechst 33258 co-stained HeLa cells exhibited red fluorescence in the whole cytoplasm when excited with TP mode at $820 \mathrm{~nm}$ (Fig. 2a), while the cells showed blue fluorescence in the nucleus region when excited with one-photon mode at $405 \mathrm{~nm}$ (Fig. 2b). The merged images (Fig. 2c) further prove that the NRNO probe can be easily
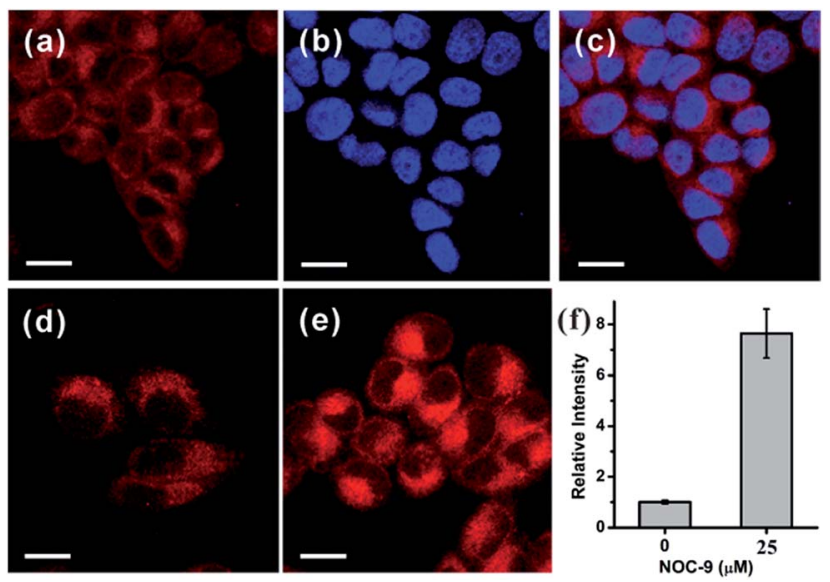

Fig. 2 (a) TP and (b) one-photon images of HeLa cells co-stained with $5.0 \mu \mathrm{M}$ NRNO and $1.0 \mu \mathrm{M}$ Hoechst 33258 for $30 \mathrm{~min}$. (c) Merged images of (a) and (b). (d) TP image of $5.0 \mu \mathrm{M}$ NRNO-loaded HeLa cells. (e) TP image of HeLa cells loaded with $5.0 \mu \mathrm{M}$ NRNO and then incubated with $25 \mu \mathrm{M}$ NOC-9 for $30 \mathrm{~min}$. (f) Relative TP fluorescence intensity in (d) and (e). The excitation wavelength for one-photon and two-photon imaging were $405 \mathrm{~nm}$ and $820 \mathrm{~nm}$, respectively, and the emissions were collected at 420-500 nm for Hoechst 33258 and 620-700 nm, respectively for NRNO. Scale bars: $10 \mu \mathrm{m}$. 
loaded into cytoplasm without any leakage and the cells are viable throughout the imaging experiments. To test the ability of the probe to respond to exogenous NO in living cells, HeLa cells were incubated with $5.0 \mu \mathrm{M}$ NRNO followed by incubation with $25 \mu \mathrm{M}$ NOC-9, a recognized NO donor. ${ }^{19}$ As demonstrated in Fig. $2 \mathrm{~d}$ and e, the red fluorescence in the cytoplasm region was significantly enhanced (7.4-fold, as quantitatively calculated and presented in Fig. 2f) after incubating with NOC-9 for $30 \mathrm{~min}$. These results confirm the capability of NRNO to detect exogenous NO in living cells.

Motivated by the above results, we further tried to use the probe to monitor the change in endogenously generated nitric oxide in living cells under a two-photon microscope. There are previous reports on the NO production in RAW 264.7 cells stimulated by bacterial LPS and IFN- $\gamma .^{20}$ We therefore selected this cell model for the endogenous NO observations. As shown in Fig. 3a, RAW 264.7 cells treated with only NRNO showed moderate red fluorescence, which could have originated from the probe itself and the intrinsic basal NO. When the cells were pre-treated with $20 \mu \mathrm{g} \mathrm{mL} \mathrm{m}^{-1} \mathrm{LPS}, 200 \mathrm{U} \mathrm{mL}^{-1} \mathrm{IFN}-\gamma$ and $0.5 \mathrm{mg}$ $\mathrm{mL}^{-1} \mathrm{~L}$-arginine (the substrate for nitric oxide synthase) before the loading of the probe, a remarkable enhancement of fluorescence intensity was observed (Fig. 3b). To further prove that the enhanced fluorescence was induced by nitric oxide, we performed another control set where the cells were pre-treated with LPS, IFN- $\gamma$ and L-arginine, together with $10 \mu \mathrm{M} \mathrm{L}-\mathrm{N}^{\mathrm{G}}$ nitroarginine (L-NNA), which is a known inducible NO synthase (iNOS) inhibitor. ${ }^{21}$ In this case, the fluorescence intensity was
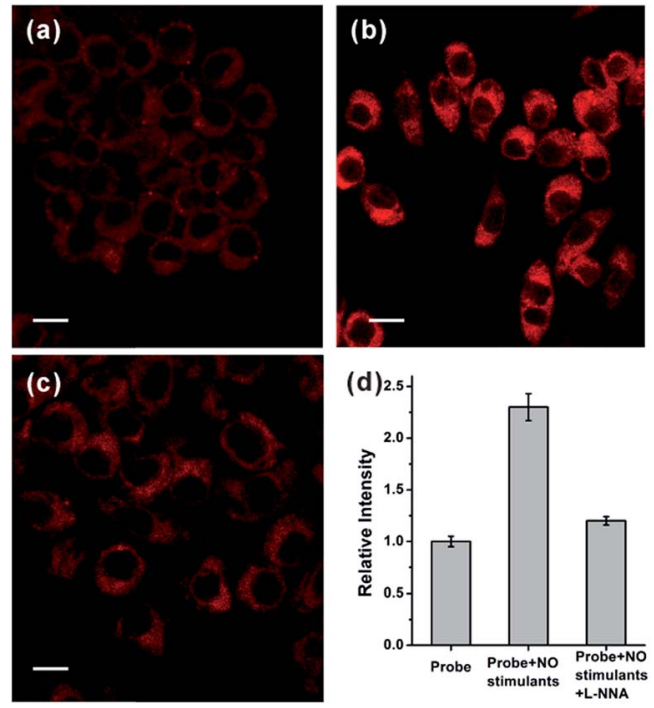

Fig. 3 (a) TP image of RAW 264.7 cells incubated with $5.0 \mu M$ NRNO for $30 \mathrm{~min}$. (b) TP image of RAW 264.7 cells pre-treated with NO stimulants $\left(20 \mu \mathrm{g} \mathrm{mL}^{-1}\right.$ LPS, $200 \mathrm{U} \mathrm{mL}^{-1} \mathrm{IFN}-\gamma$ and $0.5 \mathrm{mg} \mathrm{mL}^{-1} \mathrm{~L}$ arginine) for 14 hours before incubation with $5.0 \mu \mathrm{M}$ NRNO for $30 \mathrm{~min}$. (c) TP image of RAW 264.7 cells pre-treated with NO stimulants ( $20 \mu \mathrm{g}$ $\mathrm{mL}^{-1} \mathrm{LPS}, 200 \mathrm{U} \mathrm{mL}^{-1}$ IFN- $\gamma, 0.5 \mathrm{mg} \mathrm{mL}^{-1}$ L-arginine) and $10 \mu \mathrm{M} \mathrm{L-}$ NNA for 14 hours, before incubation with $5.0 \mu \mathrm{M}$ NRNO for $30 \mathrm{~min}$. (d) Relative TP fluorescence intensities in $(a-c)$. The excitation wavelength for TP imaging was $820 \mathrm{~nm}$ and the emission was collected at 620-700 nm. Scale bar: $10 \mu \mathrm{m}$. almost attenuated to the basal level (Fig. 3c and d). These results have unambiguously confirmed that the NRNO probe is capable of monitoring the fluctuation of endogenously generated NO in living cells.

\section{TP tissue imaging of NO generation in an inflamed mouse model}

After verifying the ability of NRNO to track both exogenous and endogenous NO in living cells, we attempted to show the in vivo applicability of this far-red emissive TP probe. Firstly, we checked the possibility of using the probe to stain and respond to NO in mouse liver tissues. To this end, TP imaging of nitric oxide in tissue slices of mouse liver was carried out. As shown in Fig. 4, a similar trend to that in living cells was obtained, i.e., the NRNO stained tissue displayed quite weak fluorescence (Fig. 4a), whereas, the tissue treated with both NRNO and excess NO exhibited much brighter fluorescence (Fig. 4b). The significant change in TP fluorescence intensity proved that the probe is suitable for the detection of NO in deep tissues. By using the z-scan mode of the TP microscope, the fluorescence intensities at different depths of mouse liver tissue were recorded (Fig. 4c and Fig. S7 $†$ ). The accumulated images obtained with z-scan revealed that the NRNO probe can homogeneously stain the tissues, and that it is able to visualize NO at depths of up to $168 \mu \mathrm{m}$ in mouse liver tissues under TP excitation.

Immunology research has demonstrated that iNOS is highly expressed during infection and inflammation in the innate immune system, and high amounts of NO and other reactive nitrogen species are generated. These reactive nitrogen species exert toxic effects on invading bacteria or viruses via nitrosation and nitration of DNA, as well as oxidative inactivation of ironsulfur centers, microbial proteins and cell wall components. ${ }^{22}$ It was also reported that LPS can cause inflammation in
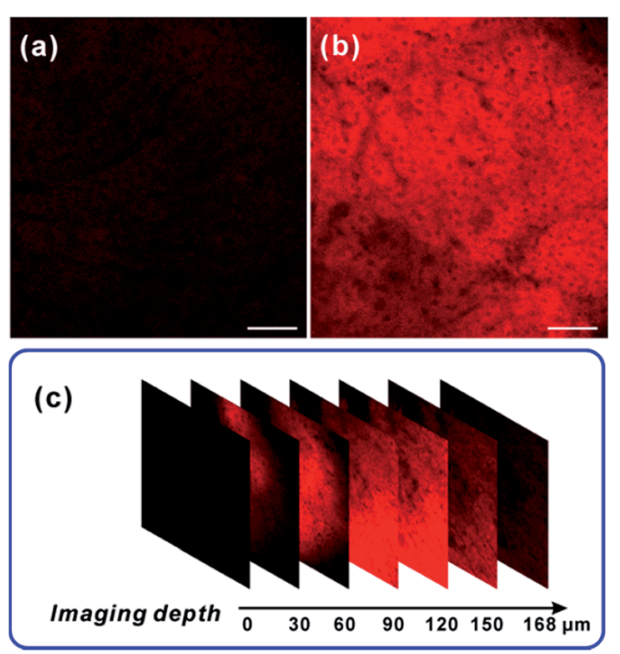

Fig. 4 TP images of mouse liver slices at $90 \mu \mathrm{m}$ depth, stained with $10 \mu \mathrm{M}$ of NRNO for $1.5 \mathrm{~h}$ (a) and then with $60 \mu \mathrm{M} \mathrm{NO}$ for another $1 \mathrm{~h}$ (b). (c) The confocal $z$-scan TP imaging sections at different depths for 0 , $30,60,90,120,150,168 \mu \mathrm{m}$. The TP excited fluorescence was collected at $620-700 \mathrm{~nm}$ upon excitation at $820 \mathrm{~nm}$ with a femtosecond pulse laser. Scale bar: $100 \mu \mathrm{m}$. 


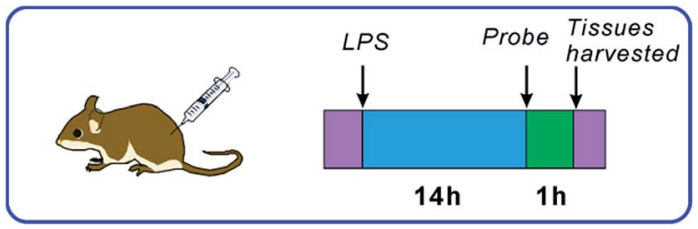

(a) (b)

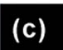

animals. ${ }^{23}$ However, so far there has been no report on monitoring NO generation in the progression of inflammation using a molecular probe. As the first trial, we utilized the NRNO probe to detect the NO production in a mouse model. To this end, $200 \mu \mathrm{L}$ of LPS solutions with various concentrations $(0,1.0,2.0$, $4.0 \mathrm{mg} \mathrm{mL} \mathrm{me}^{-1}$ ) were separately injected subcutaneously into the left rear leg of four mice to cause inflammation, followed by the injection of NRNO at the same position. The sectioned tissue slices were then subjected to TP fluorescence imaging. Interestingly, the acquired high-resolution images present vivid visualizations of $\mathrm{NO}$ production in the immune response process. As illustrated in Fig. 5a, the tissue of the mouse injected with saline only $\left(0 \mathrm{mg} \mathrm{mL}^{-1}\right.$ LPS) showed negligible fluorescence, while the tissues from mice injected with LPS exhibited notable fluorescence enhancement (Fig. 5b-d). Furthermore, the fluorescence intensity of the tissues was positively correlated with the LPS concentration (Fig. 5e), which suggests that the NO generation is dependent on the dosage of the drug and could reflect the degree of inflammation. Taken together, the results confirm that the TP excited far-red emissive NRNO is sensitive enough for measuring NO levels in deep tissues, and could be a useful indicator in monitoring NOrelated biological processes.

\section{Conclusions}

In summary, we have developed a far-red emissive, two-photon NRNO probe, for nitric oxide and demonstrated its application in detecting NO in cells and tissues by two photon microscopy.
The Nile Red-based fluorophore possesses both an adequate TP cross section and a far-red emission band centered at $650 \mathrm{~nm}$, which are favourable for deep imaging in biological samples. The probe shows fast response, high sensitivity and specificity toward nitric oxide. NRNO is able to detect exogenous NO in HeLa cells and endogenously generated NO as stimulated by drugs in RAW 264.7 cells. It also exhibits high resolution in tissue imaging at depths up to $c a .170 \mu \mathrm{m}$. The probe is applicable in the monitoring of NO generation in the LPS-mediated inflammation of mice for the first time, which reveals that the NO concentration in inflamed tissue is positively correlated with the inflammation process. The results elucidate that the NRNO probe may afford a useful tool for studying the biological events involving NO. NRNO is the first far-red emissive twophoton probe for NO, which may also promote the advancement of TP fluorescence probes with long-wavelength emission.

\section{Acknowledgements}

This work was financially supported by the National Natural Science Foundation of China (no. 21375098, 21535005).

\section{Notes and references}

1 (a) F. Murad, Angew. Chem., Int. Ed., 1999, 38, 1856-1868; (b) C. Coletta, A. Papapetropoulos, K. Erdelyi, G. Olah, K. Modis, P. Panopoulos, A. Asimakopoulou, D. Gero, I. Sharina, E. Martin and C. Szabo, Proc. Natl. Acad. Sci. U. S. A., 2012, 109, 9161-9166; (c) D. Fukumura, S. Kashiwagi and R. K. Jain, Nat. Rev. Cancer, 2006, 6, 521-534.

2 (a) M. A. Tayeh and M. A. Marletta, J. Biol. Chem., 1989, 264, 19654-19658; (b) J. O. Lundberg, M. T. Gladwin and E. Weitzberg, Nat. Rev. Drug Discovery, 2015, 14, 623-641.

3 (a) V. Calabrese, C. Mancuso, M. Calvani, E. Rizzarelli, D. A. Butterfield and A. M. Stella, Nat. Rev. Neurosci., 2007, 8, 766-775; (b) A. Castegna, V. Thongboonkerd, J. B. Klein, B. Lynn, W. R. Markesbery and D. A. Butterfield, J. Neurochem., 2003, 85, 1394-1401; (c) A. W. Carpenter and M. H. Schoenfisch, Chem. Soc. Rev., 2012, 41, 3742-3752.

4 (a) W. Xu, L. Z. Liu, M. Loizidou, M. Ahmed and I. G. Charles, Cell Res., 2002, 12, 311-320; (b) H. J. Xiang, Q. Deng, L. An, M. Guo, S. P. Yang and J. G. Liu, Chem. Commun., 2015, 52, 148-151; (c) V. Rapozzi, D. Ragno, A. Guerrini, C. Ferroni, E. della Pietra, D. Cesselli, G. Castoria, M. Di Donato, E. Saracino, V. Benfenati and G. Varchi, Bioconjugate Chem., 2015, 26, 1662-1671.

5 (a) E. W. Miller and C. J. Chang, Curr. Opin. Chem. Biol., 2007, 11, 620-625; (b) X. Chen, X. Tian, I. Shin and J. Yoon, Chem. Soc. Rev., 2011, 40, 4783-4804; (c) X. Li, X. Gao, W. Shi and H. Ma, Chem. Rev., 2014, 114, 590-659; (d) Y. Yang, S. K. Seidlits, M. M. Adams, V. M. Lynch, C. E. Schmidt, E. V. Anslyn and J. B. Shear, J. Am. Chem. Soc., 2010, 132, 13114-13116; (e) L. Yuan, W. Lin, Y. Xie, B. Chen and S. Zhu, J. Am. Chem. Soc., 2012, 134, 1305-1315; $(f)$ Z. Xu and L. Xu, Chem. Commun., 2016, 52, 1094-1119; $(g)$ E. Sasaki, H. Kojima, H. Nishimatsu, Y. Urano, K. Kikuchi, Y. Hirata and T. Nagano, J. Am. Chem. Soc., 2005, 127, 
3684-3685; (h) X. Sun, G. Kim, Y. Xu, J. Yoon and T. D. James, ChemPlusChem, 2016, 81, 30-34; (i) M. D. Pluth, L. E. McQuade and S. J. Lippard, Org. Lett., 2010, 12, 23182321; (j) C. Sun, W. Shi, Y. Song, W. Chen and H. Ma, Chem. Commun., 2011, 47, 8638-8640; (k) C.-B. Huang, J. Huang and L. Xu, RSC Adv., 2015, 5, 13307-13310.

6 H. Kobayashi, M. Ogawa, R. Alford, P. L. Choyke and Y. Urano, Chem. Rev., 2010, 110, 2620-2640.

7 (a) H. M. Kim and B. R. Cho, Chem. Rev., 2015, 115, 50145055; (b) G. S. He, L. S. Tan, Q. Zheng and P. N. Prasad, Chem. Rev., 2008, 108, 1245-1330.

8 (a) E. W. Seo, J. H. Han, C. H. Heo, J. H. Shin, H. M. Kim and B. R. Cho, Chem.-Eur. J., 2012, 18, 12388-12394; (b) H. Yu, Y. Xiao and L. Jin, J. Am. Chem. Soc., 2012, 134, 1748617489; (c) X. Dong, C. H. Heo, S. Chen, H. M. Kim and Z. Liu, Anal. Chem., 2014, 86, 308-311.

9 (a) W. R. Zipfel, R. M. Williams, R. Christie, A. Y. Nikitin, B. T. Hyman and W. W. Webb, Proc. Natl. Acad. Sci. U. S. A., 2003, 100, 7075-7080; (b) D. Kim, H. Moon, S. H. Baik, S. Singha, Y. W. Jun, T. Wang, K. H. Kim, B. S. Park, J. Jung, I. Mook-Jung and K. H. Ahn, J. Am. Chem. Soc., 2015, 137, 6781-6789.

10 (a) A. Shao, Y. Xie, S. Zhu, Z. Guo, S. Zhu, J. Guo, P. Shi, T. D. James, H. Tian and W. H. Zhu, Angew. Chem., Int. Ed., 2015, 54, 7275-7280; (b) Y.-J. Gong, X.-B. Zhang, G.-J. Mao, L. Su, H.-M. Meng, W. Tan, S. Feng and G. Zhang, Chem. Sci., 2016, 7, 2275-2285; (c) H. Chen, Y. Tang, M. Ren and W. Lin, Chem. Sci., 2016, 7, 1896-1903.

11 (a) A. R. Sarkar, C. H. Heo, H. W. Lee, K. H. Park, Y. H. Suh and H. M. Kim, Anal. Chem., 2014, 86, 5638-5641; (b) H. Xiao, P. Li, W. Zhang and B. Tang, Chem. Sci., 2016, 7, 1588-1593.
12 (a) S. Kim, T. Tachikawa, M. Fujitsuka and T. Majima, J. Am. Chem. Soc., 2014, 136, 11707-11715; (b) P. Rivera-Fuentes, A. T. Wrobel, M. L. Zastrow, M. Khan, J. Georgiou, T. T. Luyben, J. C. Roder, K. Okamoto and S. J. Lippard, Chem. Sci., 2015, 6, 1944-1948.

13 (a) Z. Yang, Y. He, J. H. Lee, W. S. Chae, W. X. Ren, J. H. Lee, C. Kang and J. S. Kim, Chem. Commun., 2014, 50, 1167211675; (b) J. Lu, Y. Song, W. Shi, X. Li and H. Ma, Sens. Actuators, B, 2012, 161, 615-620.

14 (a) S. Sumalekshmy and C. J. Fahrni, Chem. Mater., 2011, 23, 483-500; (b) M. Pawlicki, H. A. Collins, R. G. Denning and H. L. Anderson, Angew. Chem., Int. Ed., 2009, 48, 3244-3266.

15 X. Zhou, S. Lee, Z. Xu and J. Yoon, Chem. Rev., 2015, 115, 7944-8000.

16 H. Takakura, R. Kojima, M. Kamiya, E. Kobayashi, T. Komatsu, T. Ueno, T. Terai, K. Hanaoka, T. Nagano and Y. Urano, J. Am. Chem. Soc., 2015, 137, 4010-4013.

17 H. Li and A. Wan, Analyst, 2015, 140, 7129-7141.

18 S. C. Dodani, S. C. Leary, P. A. Cobine, D. R. Winge and C. J. Chang, J. Am. Chem. Soc., 2011, 133, 8606-8616.

19 A. H. Joseph, R. K. John, A. W. David and K. K. Larry, J. Org. Chem., 1993, 58, 1472-1476.

20 (a) Y. Li, W. Wu, J. Yang, L. Yuan, C. Liu, J. Zheng and R. Yang, Chem. Sci., 2016, 7, 1920-1925; (b) H. Yu, X. Zhang, Y. Xiao, W. Zou, L. Wang and L. Jin, Anal. Chem., 2013, 85, 7076-7084.

21 J. Miao, Y. Huo, X. Lv, Z. Li, H. Cao, H. Shi, Y. Shi and W. Guo, Biomaterials, 2016, 78, 11-19.

22 V. Bronte and P. Zanovello, Nat. Rev. Immunol., 2005, 5, 641654.

23 K. Kundu, S. F. Knight, N. Willett, S. Lee, W. R. Taylor and N. Murthy, Angew. Chem., Int. Ed., 2009, 48, 299-303. 